\title{
Evaluating the Effect of Metal Interference in Inhibition of Biofilm Formation by Uropathogenic Escherichia coli Isolated From Hospitalized Patients
}

\author{
Fatemeh Khazaei $^{{ }^{*}}$, Somayeh Talebi², Farzaneh Hosseini ${ }^{3}$ \\ ${ }^{1}$ Department of Microbiology, Karaj Branch, Islamic Azad University, Karaj, Iran. \\ ${ }^{2}$ Department of Microbiology, Faculty of Basic Sciences, Tehran Medical Sciences, Islamic Azad University, Tehran, Iran \\ ${ }^{3}$ Department of Microbiology, Tehran North Branch, Islamic Azad University, Tehran, Iran
}

\section{*Correspondence to Fatemeh Khazaei, Department of Microbiology, Karaj Branch, Islamic Azad University, Karaj, Iran. Tel: +98912 737 4053, Email: khazaeif6@gmail.com}

Received March 2, 2018 Accepted May 13, 2018 Published online December 31 , 2018

\begin{abstract}
Introduction: Bacteria that are able to form biofilms can lead to chronic antibiotic-resistant infections and immunomodulatory effects. Iron and other bivalent metals are essential requirements for biofilm formation by bacteria. Escherichia coli is the most predominant agent causing urinary tract infection (UTI). This study aimed to assess the effects of bivalent metals (iron, zinc, cobalt, and copper) on biofilm formation by $E$. coli isolated from hospitalized patients suffering from UTI. Methods: A total of 110 E. coli were isolated from 200 UTI patients referred to Farmanieh hospital in Tehran, Iran. E. coli was confirmed by culture specific media, biochemical tests, and polymerase chain reaction (PCR) analysis. To determine the antibiotic resistance, the Kirby-Bauer disk method was used and the biofilm formation was assessed using microtiter plate assay and electron microscopy. Finally, the data were analyzed via paired t test using the SPSS software.

Results: Based on our results, out of 110 urine samples containing E. coli, the highest and the lowest resistance were observed to ampicillin (90\%) and amikacin (53\%), respectively. The biofilm development was intensified in the presence of glucose and iron. The results also indicated that biofilm formation was inhibited by the use of bivalent metal ions including zinc, cobalt, and copper, with the maximum effect obtained for zinc $(P<0.05)$.

Conclusion: Our work led us to conclude that zinc, cobalt, and copper can inhibit biofilm formation by bacterial strains in medicine.

Keywords: Biofilm, E. coli, Urinary tract infection
\end{abstract}

\section{Introduction}

Biofilm-forming uropathogenic bacteria are responsible for many recurrent urinary tract infections (UTIs). Escherichia coli is a prevalent bacterium which leads to UTI in all age groups especially in hospital environments. ${ }^{1}$ E. coli is in fact the most common cause of UTI. Biofilm protects uropathogenic E. coli (UPEC) from the antibiotics and host immune system and accordingly provides a reservoir for persistent infection. ${ }^{2}$ UPEC can also form biofilms on catheters, leading to catheterassociated UTIs (CAUTIs), and E. coli is the leading cause of these infections. ${ }^{3}$

Biofilms are assemblages of cell-cell or solid surface-microbial attachments which are established in a hydrated self-produced matrix. Biofilm matrix containing polysaccharides, proteins, and extracellular DNA (eDNA) is responsible for the attachment to the surfaces of the biofilms. ${ }^{4}$ Five steps required for biofilm formation are: (1) reversible attachment of planktonic bacteria to the surface; (2) irreversible attachment to the surface; (3) establishment of the external matrix and extracellular polymeric substance (EPS); (4) biofilm maturation by forming 3-dimensional structure; and (5) biofilm breakdown. ${ }^{5}$ Biofilms are widely distributed and can be found in different places and niches. Biofilm generation is a mechanism by which bacteria manage to survive in

(C) 2018 The Author(s); Published by Zabol University of Medical Sciences. This is an open-access article distributed under the terms of the Creative Commons Attribution License (http://creativecommons.org/licenses/by/4.0), which permits unrestricted use, distribution, and reproduction in any medium, provided the original work is properly cited. 
unfavorable situations. ${ }^{6}$ Biofilms are responsible for $80 \%$ of all microbial infections and for over $65 \%$ of nosocomial infections. They protect pathogenic bacterial species from antimicrobial drugs and host immune responses. ${ }^{7}$

Iron is an essential element required for bacterial growth and energy production, as well as gene expression regulation. Iron tropism often limits the host accessibility in order to incorporate the iron into the proteins such as hemoglobin, transferrin, lactoferrin, and ferritin and in this way prevents the recruitment of iron by bacteria. ${ }^{8}$

To establish infection in the human body, pathogenic bacteria acquire iron from host sources through varying iron absorption mechanisms. For example, siderophores constitute a common strategy for the uptake of iron by microorganisms. ${ }^{9}$

Iron is also required for biofilm formation in several bacteria such as Pseudomonas aeruginosa, and E. coli. ${ }^{10}$ Recent works have found that adequate iron can promote the formation of biofilm by bacteria.

Additionally, iron can modulate gene expression by activating the iron-starvation-induced genes. A regulator protein known as Fur is the main regulator of ferric uptake in E. coli. ${ }^{11}$

Furthermore, Fur protein both positively and negatively regulates gene expression in E. coli via interactions with its corepressor, Fe (II). It has been noted that inadequate iron can inhibit E. coli biofilm formation. Researchers believe Zn (II) and Co (II) may negatively affect E. coli biofilm formation as these elements in comparison with iron have higher affinity for the Fur, the master regulator. ${ }^{12}$ Therefore, the current study aimed to assess the effects of bivalent metals (zinc, cobalt, and copper) on biofilm formation by $E$. coli isolated from hospitalized patients suffering from UTI, referred to Farmanieh hospital in Tehran, Iran.

\section{Materials and Methods}

Escherichia coli Culture

A total of 200 urine samples were obtained from patients suffering from UIT referred to the Farmanieh hospital in Tehran, Iran. Bacterial cells were grown on EMB (Eosin Methylene Blue) agar, MacConkey agar, Triple Sugar Iron (TSI) agar, Simon Citrate, SIM (Sulfide Indole Motility), Urea agar, Methyl Red-Voges Proskauer (MR-VP), and Lysin Iron agar. The antimicrobial susceptibility was determined by the Kirby-Bauer method. Seven routine antibiotic discs including ampicillin $(10 \mu \mathrm{g})$, amikacin (30 $\mu \mathrm{g})$, gentamicin $(10 \mu \mathrm{g})$, cotrimoxazole $(25 \mu \mathrm{g})$, ciprofloxacin $(5 \mu \mathrm{g})$, nalidixic $(30 \mu \mathrm{g})$, and nitrofurantoin $(300 \mu \mathrm{g})$ were used in this study. All the antibiotics were purchased from Kowsar Company (Tehran, Iran).

Escherichia coli isolation was confirmed using common biochemical tests including TSI, SIM, Simon Citrate, MR-VP, ONPG disk, OF, Lysin iron agar, and urea for detection of enterobacteriaceae. The Kirby-Bauer method was used to determine antibiotic resistance. Finally, gram staining was employed to determine gram negative $E$. coli. Suspension equivalent to $0.5 \mathrm{McF}$ arland $\left(1.5 \times 10^{8}\right.$ $\mathrm{cfu} / \mathrm{mL}$ ) was cultured on MHA medium. The antibiotic disks were applied at $37^{\circ} \mathrm{C}$ for 24 hours. Inhibition zone diameter was measured.

Reverse Transcription Polymerase Chain Reaction RNase free DNase was used to remove DNA contamination from total bacterial RNA. Subsequently, high capacity cDNA Reverse Transcription kit (Applied biosystems, USA) was used and cDNA was prepared according to the manufacturer's instructions. Polymerase chain reaction (PCR) was performed for detection of fur gene using the appropriate forward primer: 5'-GTACCTGTGGGGCTCATTGT-3' and reverse primer: 5'-CTGCCCTTGCAGATACCATT-3'. PCR was performed as: initial denaturation at $94^{\circ} \mathrm{C}$ for 3 minutes, 35 cycles of denaturation at $94^{\circ} \mathrm{C}$ for 30 seconds, annealing at $60^{\circ} \mathrm{C}$ for 30 seconds, extension at $72^{\circ} \mathrm{C}$ for 30 seconds, and final extension at $72^{\circ} \mathrm{C}$ for 7 minutes. The samples were run on $1 \%$ agarose gel to visualize bands.

\section{Biofilm Formation}

In microtiter plates, the ability of biofilm formation was assessed according to the method of O'Toole and Kolter ${ }^{13}$ and Vieira et $\mathrm{al}^{14}$ with slight modifications. All the isolates in a nutshell were incubated $\left(37^{\circ} \mathrm{C}\right)$ in the nutrient agar (Merck, Germany) overnight, and then cultured in $\mathrm{LB}$ medium at $37^{\circ} \mathrm{C}$ for 24 hours. The bacterial cell suspension density was set to represent the Optical densities (ODs) of 0.45 to 0.65 at $600 \mathrm{~nm}$. Then, $10 \mu \mathrm{L}$ of the bacterial suspension was transferred to 96 -well plates. Subsequently, LB medium $(190 \mu \mathrm{L})$ was poured into each well and incubation was continued at $37^{\circ} \mathrm{C}$ for 24 hours without shaking. A volume of $200 \mu \mathrm{L} \mathrm{LB}$ medium was added to one of the wells as negative control. After 24 hours incubation, the plates were smoothly rinsed with saline buffer to discard loosely attached bacteria. In the final step, the extra buffer was discarded and the biofilms were dried up in air for 10 minutes. To stain the wells, they were incubated with $200 \mu \mathrm{L}$ crystal violet (CV) $0.5 \%$ in $\mathrm{H}_{2} \mathrm{O}$ (15 minutes at room temperature). The CV stain was removed and sterile distilled water was used to wash the wells for 3 times. The mixture of $80 \%$ ethanol and $20 \%$ acetone $(200 \mu \mathrm{L})$ was added to remove the $\mathrm{CV}(15$ minutes at room temperature). Finally, the OD was determined by microtiter plate reader at $492 \mathrm{~nm}$. All of these steps were performed for 48 hours, 72 hours, and one week in triplicate. Moreover, to obtain thicker biofilms, glucose $(0.001 \mathrm{~g})$ or bivalent iron was added to the brain heart infusion (BHI) broth medium for activating the Fur protein.

Biofilm Formation on Catheters

Biofilm formation under hydrodynamic conditions was evaluated on $100 \%$ silicone Foley catheters. ${ }^{15}$ The catheter 
fragments were cut into $2-\mathrm{cm}$ length pieces, and each piece was placed on a glass tube and sterilized in autoclave at $121^{\circ} \mathrm{C}$ for 15 minutes under 15 psi of pressure. At first, catheter fragments were washed with $50 \mathrm{~mL}$ of phosphatebuffered saline (PBS) for 3 times. To avoid the influence of free or loosely attached bacteria, the additional liquid was removed with capillarity absorbent paper. The tubes were then inoculated with $\mathrm{BHI}$ broth containing freshly grown E. coli bacteria. To increase the thickness of the biofilm, $0.001 \mathrm{~g}$ glucose as well as $0.0001 \mathrm{~g}$ iron were added and incubated at $37^{\circ} \mathrm{C}$ for 1 week. For biofilm formation, different conditions were considered on microtiter plates. After staining with CV, the OD was read by ELISA reader. Biofilm formation steps were followed for 48 hours, 72 hours, and 1 week. The experiments were repeated 6 times and the best conditions for biofilm formation were selected. Afterward, electron microscopy was used to confirm the biofilm formation.

Biofilm Inhibition Assay

To evaluate inhibition of biofilm formation, bivalent cations (zinc, cobalt, and copper) with more affinity for Fur proteins than iron were used. In this regard, in a BHI broth tube previously inoculated with bacterial suspension and glucose and iron, $0.0001 \mathrm{~g}$ of each of the zinc, cobalt, or copper bivalent cations were added. Electron microscopy was used to assess biofilm formation after 1 week of incubation. Each stage of the experiment was followed by a positive control (maximum biofilm formation) and a negative control (no biofilm formation).

\section{Scanning Electron Microscopy Visualization}

The sample preparation steps included (1) washing the samples with PBS (to remove contamination); (2) fixing the samples with glutaraldehyde $2.5 \%$ for 1 hour at $4^{\circ} \mathrm{C}$; (3) washing the samples with buffer for 15 minutes; (4) fixing the samples with tetraoxide osmium for 30 minutes at room temperature; (5) dehydrating the samples by immersing in increasing alcohol concentrations (50\%, $70 \%, 90 \%$, and $100 \%$ ) for 3 times; and (6) drying in desiccator for 24 hours. After preparing the samples for observation under electron microscope, they were coated with gold, and viewed at $15 \mathrm{kV}$ and magnifications of 4000, 10000,15000 , and 20000.

\section{Statistical Analysis}

The data were analyzed by the SPSS software version 19.0 using paired $t$ test and a $P$ value $<0.05$ was considered statistically significant.

\section{Results}

Culture of Urine Samples Isolated From Patients With UTI

All 200 urine samples were cultured on routine culture media (i.e., EMB, Blood agar, and Chocolate agar) for detecting E. coli and other bacteria (Table 1).
Table 1. Percentage of Isolated Bacterial Strains Obtained From 200 Patients With Urinary Tract Infection

\begin{tabular}{lcc}
\hline Isolate & Number & Percent \\
\hline E. coli & 110 & 55 \\
K. pneumoniae & 40 & 20 \\
P. aeruginosa & 20 & 10 \\
Acinetobacter sp. & 11 & 5 \\
Proteus sp. & 7 & 0.03 \\
Gram-positive bacteria & 12 & 0.06 \\
Total & 200 & \\
\hline
\end{tabular}

\section{RT-PCR for Detection of fur Gene}

After biochemical identification of the isolated $E$. coli bacteria, PCR analysis was used for molecular identification of fur gene. The presence of a $310 \mathrm{bp}$ band confirmed the strains as E. coli. Figure 1 demonstrates the expression of the fur genes in the mRNA isolated from the culture of six randomly-selected samples from the UTI patients.

\section{Antibiogram Results}

Antibiotic resistance was evaluated by disk diffusion Kirby-Bauer method. Overall, 100 isolates were resistant to ampicillin (90\%), 95 to cotrimoxazole (86\%), 85 to ciprofloxacin (77\%), 80 to gentamicin (72\%), 76 to nitrofurantoin $(69 \%), 65$ to nalidixic $(59 \%)$, and 59 to amikacin (53\%).

Glucose and Iron Increased Biofilm Formation The biofilm formation was studied in the presence of glucose as the nutrient and iron as an activator of the Fur protein. Our study indicated that after 72 hours and one week, the biofilm formation increased $(P<0.05)$ in the presence of $0.001 \mathrm{~g}$ glucose and $0.0001 \mathrm{~g}$ iron $(P<0.05)$. The highest levels of biofilm formation were noted for BHI medium + glucose + Fe group (Figure 2).

Inhibition of Escherichia coli Biofilm Formation by Zinc, Cobalt, and Copper

In the presence of $0.0001 \mathrm{~g}$ of selected metals, biofilm attachment to the surface of the plate after one week was inhibited. At $0.0001 \mathrm{~g}$ concentration, zinc, cobalt, and copper inhibited the development of biofilm by $E$. coli, isolated from patients with UTI (Figure $2 \mathrm{~A}, \mathrm{~B}$, and C). Moreover, zinc, cobalt, and copper synergistically inhibited the iron stimulatory effects on biofilm formation

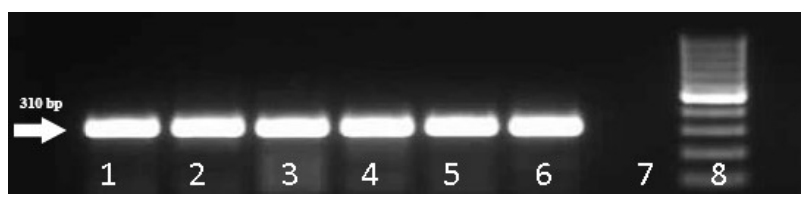

Figure 1. The Confirmation of fur Gene ( 310 bp, Lanes 1-6) by PCR, Lane 7 (Negative Control), and Lane 8 (DNA Weight Marker) 

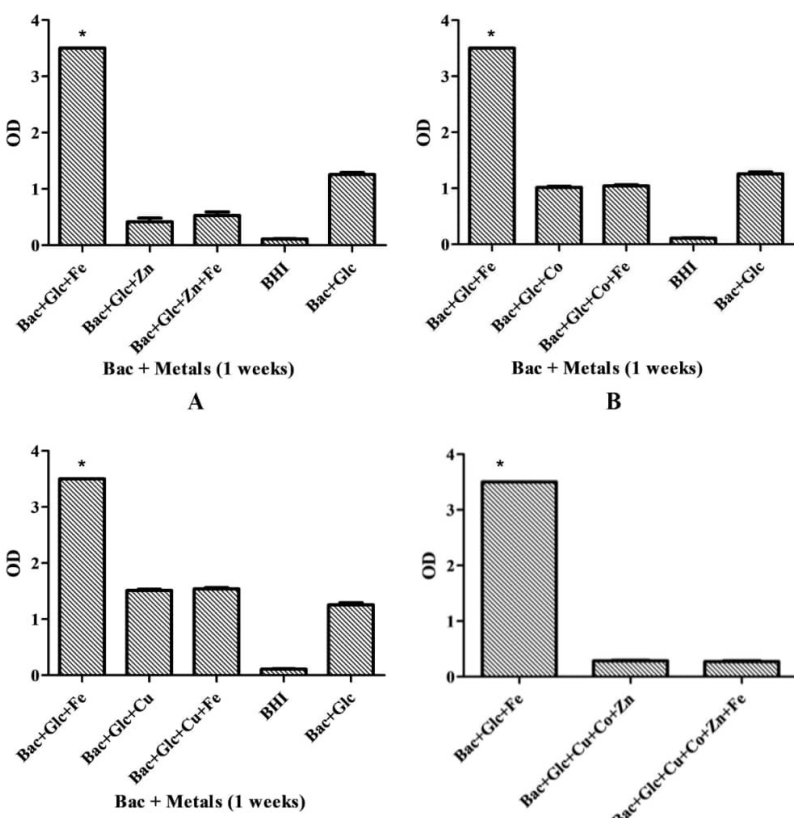

C

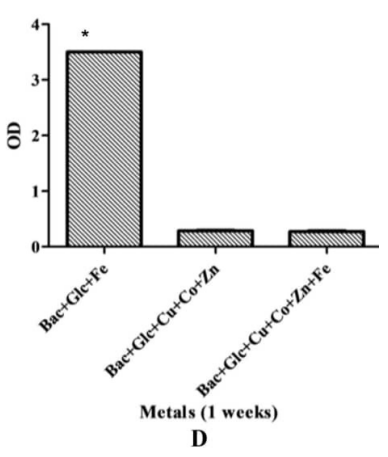

D

Figure 2. Biofilm Formation in the Presence of Zinc (A), Cobalt (B), and Copper (C). Synergistic Effects of Zinc, Cobalt, and Copper on Iron Stimulatory Effects in Biofilm Formation (D). ${ }^{*} P<0.05$.

\section{$(P<0.05)$ (Figure $2 \mathrm{D})$.}

\section{Electron Microscopy}

Figure 3 shows the biofilm formation in the presence of glucose $(\mathrm{A})$, iron $(\mathrm{B})$, or both $(\mathrm{C})$ at the magnifications of 20000,10000 and 4000. The results obtained from electron microscopy confirmed the results from microplate method. In subsequent investigations, the addition of zinc, cobalt and copper metals also confirmed the inhibition of biofilm formation. Figure 4 displays the dipped biofilms in the presence of these metals.

\section{Discussion}

Bacterial biofilms are somehow responsible for the resistance in bacterial infections. Eradicating biofilmforming bacteria is important, as these bacteria are extensively resistant to immune defense mechanisms and antibiotics. ${ }^{16}$ UTIs are common bacterial infections threatening the health and life of millions of people each year. UTI is a prominent clinical condition in patients with indwelling urinary catheters whom will expose to UTI in one month. ${ }^{17}$ E. coli and Klebsiella are 2 major UTI causing bacteria which are also potent biofilm forming bacteria.$^{18}$ Considering the persistent and resistant nature of infections caused by biofilm-forming bacteria, the recognition of antibiofilm agents is of great importance. ${ }^{19}$

In this study, E. coli bacteria were isolated from the samples of patients with UTI. The bacteria were identified using culture methods, as well as biochemical and PCR assays. A total of 200 urine samples were collected

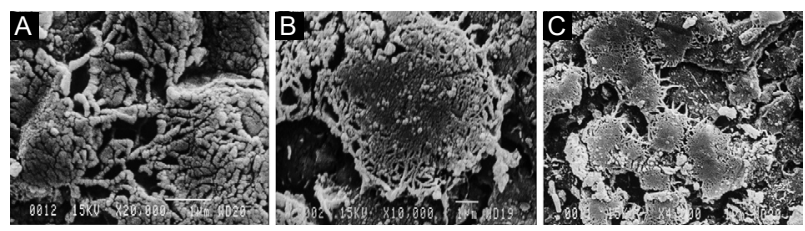

Figure 3. Biofilm Architecture Via SEM in the Presence of Glucose (A), Iron (B), and Glucose Plus Iron (C).
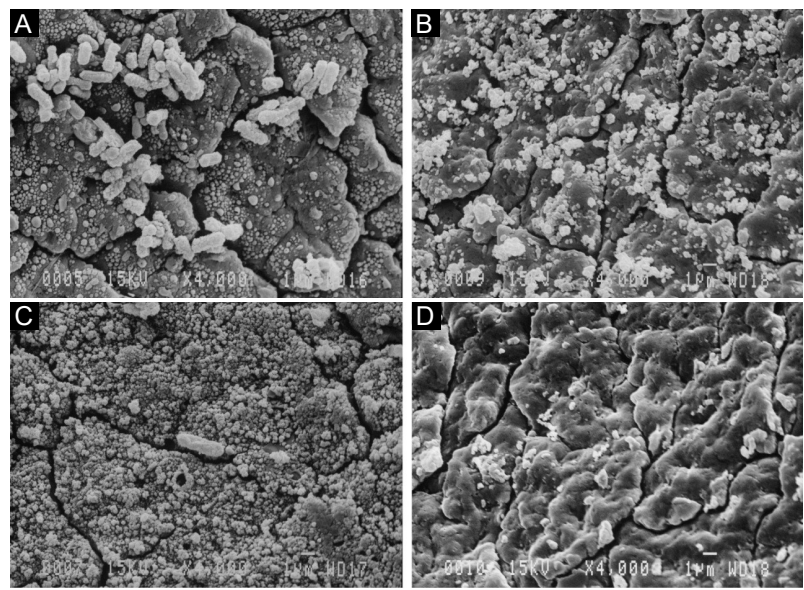

Figure 4. Inhibition of Biofilm Formation on the Surface of a Catheter in the Presence of Copper (A), Cobalt (B), and Zinc (C) Metals. The Effect of Added Copper, Cobalt, and Zinc Altogether in the Concomitant Presence of Iron (D).

from UTI patients. All of the samples were cultured on conventional growth media. Based on this culture, 110 isolates were confirmed as E. coli. Drug resistance was determined as bellows: $90 \%$ of the isolates were resistant to ampicillin, $86 \%$ to cotrimoxazole, $77 \%$ to ciprofloxacin, $72 \%$ to gentamicin, $69 \%$ to nitrofurantoin, $59 \%$ to nalidixic, and 53\% to amikacin. Our results were in agreement with the findings of Salih and Al-Ani, ${ }^{20}$ who showed that E. coli was the most usual uropathogenic bacterium after Klebsiella sp. Similarly, Niveditha et $\mathrm{al}^{21}$ reported that majority of the UTI-causing bacteria were attributed to UPEC (70\%). Our results were also in line with the results of Svanborg and Godaly, ${ }^{22}$ and Hedlund et al. $^{23}$ Hawaldar et al also documented that E. coli was detected in majority (80\%) of the UTIs. In another study, the prevalence of uropathogenic organisms was found to be $88 \%$ for E. coli, $4 \%$ for Staphylococcus aureus, $2 \%$ for P. aeruginosa, 2\% for Klebsiella pneumoniae, 3\% for Enterococcus, and $1 \%$ for Citrobacter koseri. ${ }^{24}$ Tayal et al ${ }^{25}$ demonstrated that all biofilm-producing isolates of $K$. pneumoniae were poorly sensitive to the tested antibiotics. The organism showed the highest sensitivity to amikacin at $65 \%$, followed by norfloxacin and nitrofurantoin with $33 \%$ sensitivity to each of them.

In the current study, we recruited microtiter plate method in order to assess the biofilm forming ability of E. coli isolates. The biofilms were further characterized by $\mathrm{CV}$ staining. Our primary aim was to assess the effects of 
bivalent metals on the potency of E. coli isolates from UTI patients in biofilm formation. Iron is a necessary bivalent metal for bacterial growth and biofilm formation. In mammals, the attachment of iron to receptor proteins such as transferrin and lactoferrin restricts iron bioavailability for bacterial growth. ${ }^{26} \mathrm{~A}$ significant association was found between biofilm forming ability and drug resistance in this study. On the other hand, biofilm formation was intensified by iron and glucose after one week. Under optimal conditions for E. coli biofilm formation, the addition of zinc, copper, and cobalt effectively blocked biofilm formation in our study. We demonstrated that bivalent metal ions, such as $\mathrm{Zn}$ (II), Co (II), and $\mathrm{Cu}$ (II) may inhibit iron uptake as they have higher affinity for the Fur protein, the divalent metal master regulator. In this regard, Chhibber et $\mathrm{al}^{28}$ observed that the combination of Co [II] and depolymerase-producing-phage significantly reduced $(P<0.05)$ the bacterial density in both newly formed as well as older biofilms, in comparison with the time when either of the agents was used alone. Lee et a ${ }^{29}$ indicated that $\mathrm{Zn}^{2+}$ and $\mathrm{ZnO}$ nanoparticles decreased virulence factor construction and $P$. aeruginosa biofilm formation without preventing planktonic growth. Trace amount of zinc is necessary for bacterial growth; while, high concentrations can be toxic. Shakerimoghaddam et $\mathrm{al}^{30}$ found that $\mathrm{ZnO}$ nanoparticles inhibited biofilm formation by UPEC isolates in a dose-dependent manner. $\mathrm{ZnO}$ nanoparticles strongly and more effectively suppressed biofilm formation at their minimum inhibitory concentration (MIC) than sub-MIC. Via biding to free thiol groups in the protein structure, zinc can alter protein function. Our results can be beneficial in developing medical devices such as urinary tract catheters, which are especially prone to bacterial biofilm formation.

\section{Conclusion}

As concluding remarks, our results suggested that biofilm formation can be prevented by applying divalent metals including zinc, cobalt, and copper. In line with the similar studies mentioned, all 3 metals can inhibit the growth of UPEC. However, zinc metal showed more potent biofilm inhibitory effect rather than copper and cobalt metals.

\section{Ethical Approval \\ Not applicable.}

\section{Competing Interests \\ None.}

\section{Acknowledgments}

The specific thanks of authors go to the staff at Farmaniyeh hospital, Tehran, Iran, for their assistance in this study.

\section{References}

1. Ramesh N, Sumathi CS, Balasubramanian V, Palaniappan R, Kannan R. Urinary tract infection and antimicrobial susceptibility pattern of extended spectrum beta lactamase producing clinical isolates. Adv Biol Res. 2008;2(5-6):7882.

2. Kunin CM. Urinary tract infections in females. Clin Infect Dis. 1994;18(1):1-10.

3. Hanna A, Berg M, Stout V, Razatos A. Role of capsular colanic acid in adhesion of uropathogenic Escherichia coli. Appl Environ Microbiol. 2003;69(8):4474-4481. doi:10.1128/AEM.69.8.4474-4481.2003

4. Karatan E, Watnick P. Signals, regulatory networks, and materials that build and break bacterial biofilms. Microbiol Mol Biol Rev. 2009;73(2):310-347. doi:10.1128/ mmbr.00041-08

5. Serra DO, Richter AM, Hengge R. Cellulose as an architectural element in spatially structured Escherichia coli biofilms. J Bacteriol. 2013;195(24):5540-5554. doi:10.1128/ jb.00946-13

6. Karatan E, Watnick P. Signals, regulatory networks, and materials that build and break bacterial biofilms. Microbiol Mol Biol Rev. 2009;73(2):310-347. doi:10.1128/ mmbr.00041-08

7. Regev-Shoshani G, Ko M, Crowe A, Av-Gay Y. Comparative efficacy of commercially available and emerging antimicrobial urinary catheters against bacteriuria caused by E. coli in vitro. Urology. 2011;78(2):334-339 . doi:10.1016/j.urology.2011.02.063

8. Ratledge C, Dover LG. Iron metabolism in pathogenic bacteria. Annu Rev Microbiol. 2000;54:881-941. doi:10.1146/annurev.micro.54.1.881

9. Miethke M, Marahiel MA. Siderophore-based iron acquisition and pathogen control. Microbiol Mol Biol Rev. 2007;71(3):413-451. doi:10.1128/mmbr.00012-07

10. Wu Y, Outten FW. IscR controls iron-dependent biofilm formation in Escherichia coli by regulating type I fimbria expression. J Bacteriol. 2009;191(4):1248-1257. doi: $10.1128 / \mathrm{jb} .01086-08$

11. Musk DJ, Banko DA, Hergenrother PJ. Iron salts perturb biofilm formation and disrupt existing biofilms of Pseudomonas aeruginosa. Chem Biol. 2005;12(7):789-796. doi:10.1016/j.chembiol.2005.05.007

12. Hancock V, Dahl M, Klemm P. Abolition of biofilm formation in urinary tract Escherichia coli and Klebsiella isolates by metal interference through competition for fur. Appl Environ Microbiol. 2010;76(12):3836-3841. doi:10.1128/aem.00241-10

13. O'Toole GA, Kolter R. Initiation of biofilm formation in Pseudomonas fluorescens WCS365 proceeds via multiple, convergent signalling pathways: a genetic analysis. Mol Microbiol. 1998;28(3):449-461.

14. Vieira HL, Freire P, Arraiano CM. Effect of Escherichia coli morphogene bolA on biofilms. Appl Environ Microbiol. 2004;70(9):5682-5684. doi:10.1128/aem.70.9.56825684.2004

15. Rahmani-Badi A, Sepehr S, Mohammadi A, Soudi MA, Babaie-Naiej H, Fallahi H. A combination of cis-2-decenoic acid and antibiotics eradicates pre-established catheterassociated biofilms. J Med Microbiol. 2014;63:1509-1516. doi:10.1099/jmm.0.075374-0

16. Roos V, Ulett GC, Schembri MA, Klemm P. The asymptomatic bacteriuria Escherichia coli strain 83972 
outcompetes uropathogenic E. coli strains in human urine. Infect Immun. 2006;74(1):615-624. doi:10.1128/ iai.74.1.615-624.2006

17. Stamm WE. Catheter-associated urinary tract infections: epidemiology, pathogenesis, and prevention. Am J Med. 1991;91(3b):65s-71s.

18. Ferrieres L, Hancock V, Klemm P. Specific selection for virulent urinary tract infectious Escherichia coli strains during catheter-associated biofilm formation. FEMS Immunol Med Microbiol. 2007;51(1):212-219. doi:10.1111/ j.1574-695X.2007.00296.x

19. Jacques M, Aragon V, Tremblay YD. Biofilm formation in bacterial pathogens of veterinary importance. Anim Health Res Rev. 2010;11(2):97-121. doi:10.1017/ s1466252310000149

20. Salih MT, Al-Ani NF. Microbiological aspects in biofilm produced by some uropathogens isolated from patients with indwelling bladder catheters. Rafidain J Sci. 2013;24(1):1-16.

21. Niveditha S, Pramodhini S, Umadevi S, Kumar S, Stephen $\mathrm{S}$. The isolation and the biofilm formation of uropathogens in the patients with catheter associated urinary tract infections (UTIs). J Clin Diagn Res. 2012;6(9):1478-1482. doi:10.7860/jcdr/2012/4367.2537

22. Svanborg C, Godaly G. Bacterial virulence in urinary tract infection. Infect Dis Clin North Am. 1997;11(3):513-529.

23. Hedlund M, Duan RD, Nilsson A, Svensson M, Karpman D, Svanborg C. Fimbriae, transmembrane signaling, and cell activation. J Infect Dis. 2001;183 Suppl 1:S47-50. doi:10.1086/318851

24. Hawaldar P, Patil KG, Karadesai SG. Study of biofilm formation and antibiotic resistance in urinary isolates at a tertiary care hospital in south India. Int J Health Sci Res. 2017;7(4):107-112.

25. Tayal RA, Baveja SM, De AS. Analysis of biofilm formation and antibiotic susceptibility pattern of uropathogens in patients admitted in a tertiary care hospital in India. Int J Health Allied Sci. 2015;4(4):247-252. doi:10.4103/2278344x.167648

26. Banin E, Brady KM, Greenberg EP. Chelator-induced dispersal and killing of Pseudomonas aeruginosa cells in a biofilm. Appl Environ Microbiol. 2006;72(3):2064-2069. doi:10.1128/aem.72.3.2064-2069.2006

27. Subramanian P, Shanmugam N, Sivaraman U, Kumar S, Selvaraj S. Antiobiotic resistance pattern of biofilmforming uropathogens isolated from catheterised patients in Pondicherry, India. Australas Med J. 2012;5(7):344-348. doi:10.4066/amj.2012.1193

28. Chhibber S, Nag D, Bansal S. Inhibiting biofilm formation by Klebsiella pneumoniae B5055 using an iron antagonizing molecule and a bacteriophage. BMC Microbiol. 2013;13:174. doi:10.1186/1471-2180-13-174

29. Lee JH, Kim YG, Cho MH, Lee J. ZnO nanoparticles inhibit Pseudomonas aeruginosa biofilm formation and virulence factor production. Microbiol Res. 2014;169(12):888-896. doi:10.1016/j.micres.2014.05.005

30. Shakerimoghaddam A, Ghaemi EA, Jamalli A. Zinc oxide nanoparticle reduced biofilm formation and antigen 43 expressions in uropathogenic Escherichia coli. Iran J Basic Med Sci. 2017;20(4):451-456. doi:10.22038/ ijbms.2017.8589 